\title{
Intervertebral discs: nuclear morphology and bursting pressures
}

\author{
MALCOLM I. V. JAYSON* $\dagger$, CAROL M. HERBERT* $\dagger$, AND \\ JENNIFER S. BARKS $\dagger$
}

Prolapsed intervertebral disc is a common clinical problem. It is usually thought to result from an increase in intranuclear pressure during stress exceeding the resistance of the annulus fibrosus. Artificial loading of cadaveric spines, however, has not reproduced the typical posterolateral prolapse. In general, axial loading of a vertebral column to the point of failure results in bursting of the disc contents upwards or downwards into the vertebral body rather than disruption of the annulus fibrosus.

The present study has been directed at determining the morphology of the nucleus pulposus and relating this to the intranuclear pressure necessary to produce failure. The pre-existing shape of the nucleus was also related to the site of bursting.

\section{Materials and methods}

Spines were obtained from cadavers. The vertebral columns from the first lumbar to the first sacral segments were removed intact and $x$-rayed in the anteroposterior and lateral planes. Spines that were damaged and disc spaces that showed degenerative changes were discarded. They were stored in a deep freeze and allowed to thaw for 24 hours before study.
The spines were cut into segments, each consisting of an intervertebral disc with the adjoining half vertebral bodies above and below. A specially constructed needle was inserted so that its tip lay in the centre of each disc and through this a mixture of seven parts of Conray 480 (sodium iothalamate 80 per cent.) and one part Evans blue was injected. With the needle still in place each segment was $x$-rayed in all three planes to determine the predominant morphology of the nucleus pulposus.

The appearances of the nucleus were classified into one of seven categories which are listed in Table I and illustrated in Figs 1 to 7.

The needle was then connected via high-pressure tubing to a hydraulic pump (Enpac P14) in which the hydraulic fluid had been replaced by a similar mixture of Conray 480 and Evans blue. A hydraulic gauge recorded the pressure developed in pounds per square inch $(1$ p.s.i. $=0.07 \mathrm{~kg}$. 1 sq. $\mathrm{cm} .=52 \mathrm{~mm} . \mathrm{Hg}$ ).

The spinal segment was supported between two parallel clamps, one applied to each of the cut surfaces of the vertebral bodies so preventing longitudinal expansion of the segments. With the hydraulic pump the pressure was gradually increased to the point of failure. This was readily observed as a sudden fall in pressure and was sometimes accompanied by cracking noises or visible leaks from the specimen. The pressure at which this occurred was noted.

The specimens were re- $x$-rayed in all three planes to

Table I Morphology of nuclei of intervertebral discs

\begin{tabular}{|c|c|c|}
\hline Nucleus type & Description & Figure No. \\
\hline Globular & $\begin{array}{l}\text { Nucleus is central or slightly posterior. Smooth margin. Two } \\
\text { connecting lobes one above the other may be seen on lateral } \\
x \text { ray }\end{array}$ & 1 \\
\hline Posterolateral winging & $\begin{array}{l}\text { Extension of nucleus in a posterolateral direction but not } \\
\text { reaching edge of vertebral body. Seen on axial } x \text { ray }\end{array}$ & 2 \\
\hline Posterolateral hernia & $\begin{array}{l}\text { Extension of nucleus in a posterolateral direction to reach edge } \\
\text { of vertebral body. Seen on axial } x \text { ray }\end{array}$ & 3 \\
\hline Posterior position of nucleus & $\begin{array}{l}\text { On lateral } x \text { ray the nucleus is placed posteriorly so that its } \\
\text { posterior edge is at posterior border of the vertebrae }\end{array}$ & 4 \\
\hline Irregular & $\begin{array}{l}\text { Irregular shape to nucleus with extensions in various } \\
\text { directions. Seen on axial } x \text { ray }\end{array}$ & 5 \\
\hline Central-posterior hernia & $\begin{array}{l}\text { A backwards extension from the nucleus through a narrow } \\
\text { neck to reach the posterior border of the vertebral body } \\
\text { in the midline. Seen on axial } x \text { ray }\end{array}$ & 6 \\
\hline Degenerate & Diffuse spread of dye throughout disc space & 7 \\
\hline
\end{tabular}




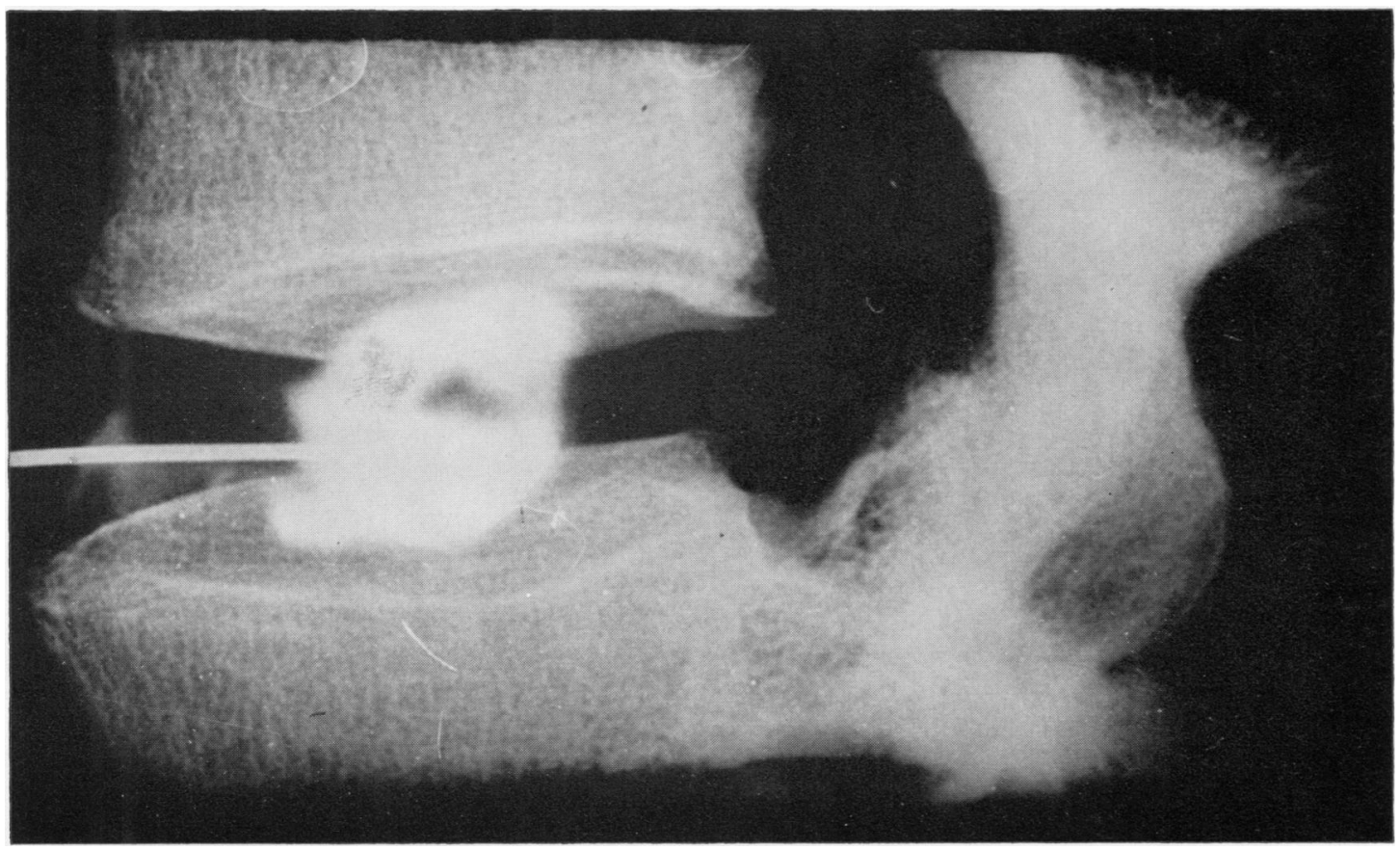

FIG. 1 Globular nucleus
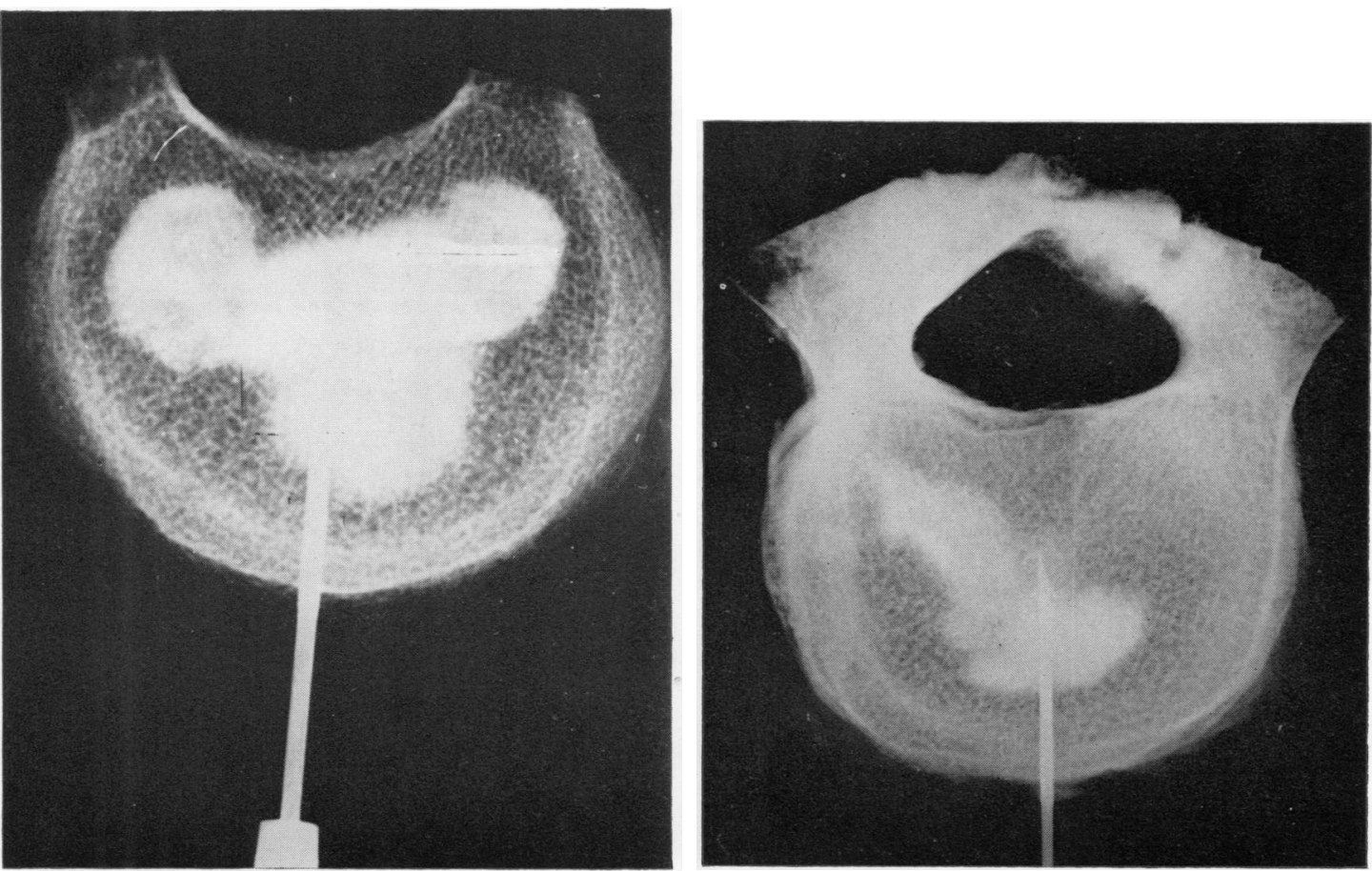

FIG. 2 Posterolateral winging of nucleus

FIG. 3 Posterolateral hernia of nucleus 


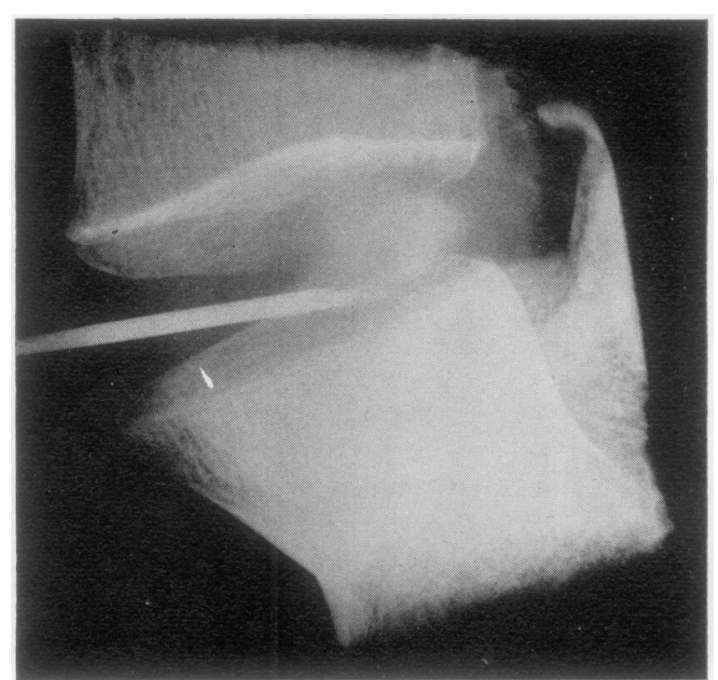

FIG. 4 Posterior position of nucleus

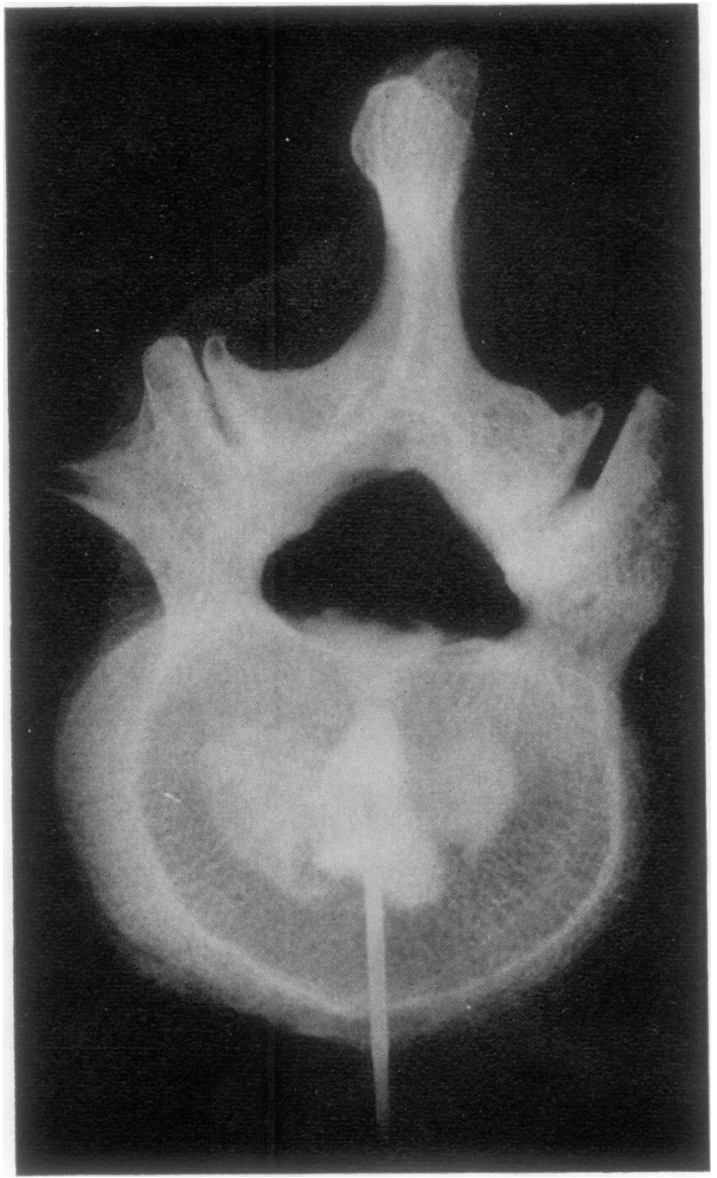

FIG. 6 Central-posterior hernia of nucleus

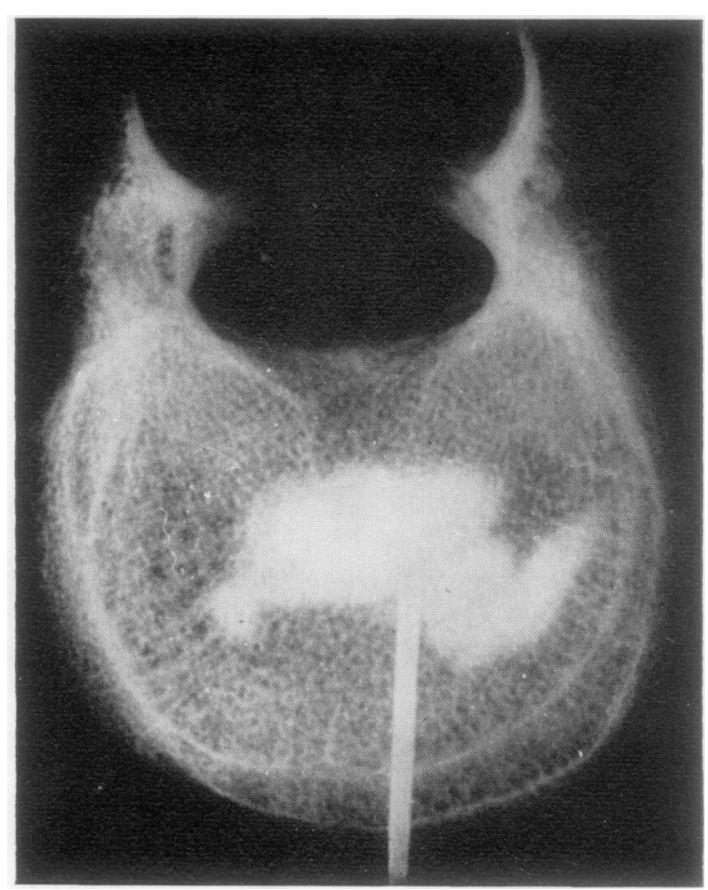

FIG. 5 Irregular nucleus

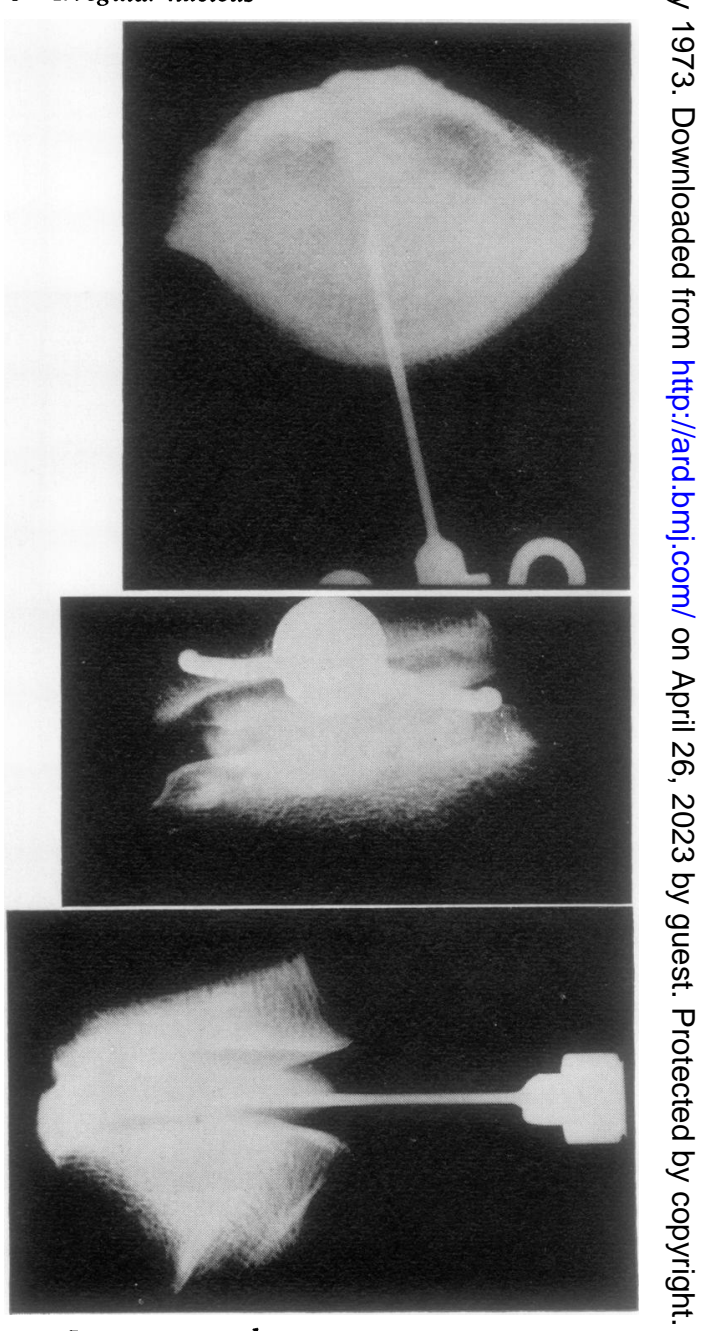

FIG. 7 Degenerate nucleus

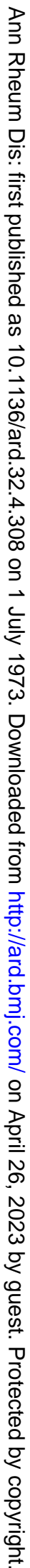


Table II Distribution of morphological changes in discs examined

\begin{tabular}{|c|c|c|c|c|c|c|}
\hline Nucleus type & $\mathrm{L} 1 / 2$ & $\mathrm{~L} 2 / 3$ & $\overline{L 3 / 4}$ & $L 4 / 5$ & L5/S1 & Total \\
\hline $\begin{array}{l}\text { Globular } \\
\text { Posterolateral winging } \\
\text { Posterolateral hernia } \\
\text { Posterior position of nucleus } \\
\text { Irregular } \\
\text { Central-posterior hernia } \\
\text { Degenerate }\end{array}$ & $\begin{array}{l}5 \\
1 \\
0 \\
0 \\
3 \\
1 \\
1\end{array}$ & $\begin{array}{l}4 \\
5 \\
1 \\
0 \\
4 \\
0 \\
1\end{array}$ & $\begin{array}{l}6 \\
8 \\
2 \\
0 \\
0 \\
2 \\
1\end{array}$ & $\begin{array}{r}10 \\
1 \\
7 \\
1 \\
0 \\
0 \\
1\end{array}$ & $\begin{array}{l}3 \\
0 \\
1 \\
3 \\
0 \\
2 \\
4\end{array}$ & $\begin{array}{r}28 \\
15 \\
11 \\
4 \\
7 \\
5 \\
8\end{array}$ \\
\hline Total & 11 & 15 & 19 & 20 & 13 & 78 \\
\hline
\end{tabular}

determine the site of failure. They were stored at $-20^{\circ} \mathrm{C}$. and later cooled further in liquid nitrogen to $-196^{\circ} \mathrm{C}$. They were then individually sliced using a band saw to study in more detail the exact sites of bursting.

\section{Results}

24 spines were examined in all, eleven from females and thirteen from males. Their ages ranged between 11 and 68 years. From these spines, 78 discs were suitable for examination, the remainder being discarded as they were damaged during removal from the body, or the radiographs showed degenerative changes.

Variations in nuclear morphology were common, the appearances being in order: globular, posterolateral winging, posterolateral hernia, degenerate, irregular, central posterior hernia, and posterior position. The distribution of discs examined together with the variations of nuclear morphology at each level are shown in Table II (above). In particular it was noted that the posterolateral winging was most frequent at the $L 2 / 3$ and $L 3 / 4$ levels, whereas posterolateral hernia occurred at the $\mathrm{L} 4 / 5$ level. As was noted by Jayson and Barks (1973), posterior position of the nucleus occurred at the L5/S1 level and in one spine at the L4/5 level, but not in the upper lumbar discs. Irregularity of the nucleus only occurred in the upper two lumbar discs and although degenerate discs were seen at all levels, they were most frequent at the L5/S1 space.

The lowest bursting pressure recorded was 50 p.s.i. At the other extreme, a number of discs failed to burst at the maximum that could be reached $-1,000$ p.s.i. For the sake of statistical analysis, these were all counted as having burst at that figure. The bursting pressures for each form of nuclear morphology are illustrated in Fig. 8 and the means tabulated in Table III. The globular discs did not differ from those showing posterolateral winging, posterior position, and irregular nucleus, whereas they were considerably higher than those showing posterolateral hernia, central posterior hernia, and degeneration, and the differences were highly significant. In addition, the discs with posterolateral winging burst at pressures which were considerably higher than those showing posterolateral hernia, and the difference was highly significant $(P<0.001)$.

It is of interest that the two globular discs that burst at the lowest pressures of 300 and $340 \mathrm{~mm}$. $\mathrm{Hg}$ respec-

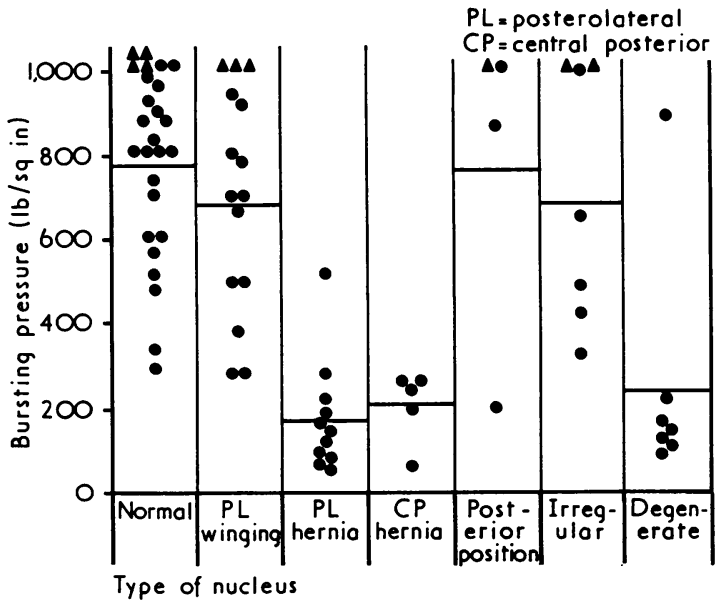

FIG. 8 Bursting pressures of the different nucleus types

Table III Bursting pressures in relation to nuclear morphology

\begin{tabular}{|c|c|c|c|}
\hline$\overline{\text { Nucleus type }}$ & $\begin{array}{l}\text { Bursting pressures } \\
\text { (p.s.i.) }\end{array}$ & $\begin{array}{l}\text { Compar } \\
\text { pressure } \\
P\end{array}$ & $\begin{array}{l}\text { sting } \\
\text { discs }\end{array}$ \\
\hline $\begin{array}{l}\text { Globular } \\
\text { Posterolateral winging } \\
\text { Posterolateral hernia } \\
\text { Posterior position of nucleus } \\
\text { Irregular } \\
\text { Central-posterior hernia } \\
\text { Degenerate }\end{array}$ & $\begin{array}{l}785 \pm 200 \\
696 \pm 249 \\
174 \pm 128 \\
765 \pm 331 \\
694 \pm 279 \\
204 \pm 75 \\
223 \pm 252\end{array}$ & $\begin{array}{l}>0.10 \\
<0.001 \\
>0.10 \\
>0.10 \\
<0.001 \\
<0.001\end{array}$ & $\begin{array}{l}\text { NS } \\
\text { HS } \\
\text { NS } \\
\text { NS } \\
\text { HS } \\
\text { HS }\end{array}$ \\
\hline
\end{tabular}


Table IV Sites of bursting in relation to nuclear morphology

\begin{tabular}{|c|c|c|c|c|c|c|}
\hline Nucleus type & $\begin{array}{l}\text { Did not } \\
\text { burst }\end{array}$ & $\begin{array}{l}\text { Burst into } \\
\text { vertebral } \\
\text { body }\end{array}$ & $\begin{array}{l}\text { Posterolateral } \\
\text { burst }\end{array}$ & $\begin{array}{l}\text { Central } \\
\text { posterior } \\
\text { burst }\end{array}$ & $\begin{array}{l}\text { Generalized } \\
\text { burst }\end{array}$ & Total \\
\hline $\begin{array}{l}\text { Globular } \\
\text { Posterolateral winging } \\
\text { Posterolateral hernia } \\
\text { Posterior position of nucleus } \\
\text { Irregular } \\
\text { Central-posterior hernia } \\
\text { Degenerate }\end{array}$ & $\begin{array}{l}4 \\
3 \\
0 \\
1 \\
2 \\
0 \\
0\end{array}$ & $\begin{array}{r}22 \\
8 \\
0 \\
1 \\
4 \\
0 \\
1\end{array}$ & $\begin{array}{r}2 \\
4 \\
11 \\
0 \\
0 \\
0 \\
0\end{array}$ & $\begin{array}{l}0 \\
0 \\
0 \\
2 \\
1 \\
5 \\
6\end{array}$ & $\begin{array}{l}0 \\
0 \\
0 \\
0 \\
0 \\
0 \\
1\end{array}$ & $\begin{array}{r}28 \\
15 \\
11 \\
4 \\
7 \\
5 \\
8\end{array}$ \\
\hline Total & 10 & 36 & 17 & 14 & 1 & 78 \\
\hline
\end{tabular}

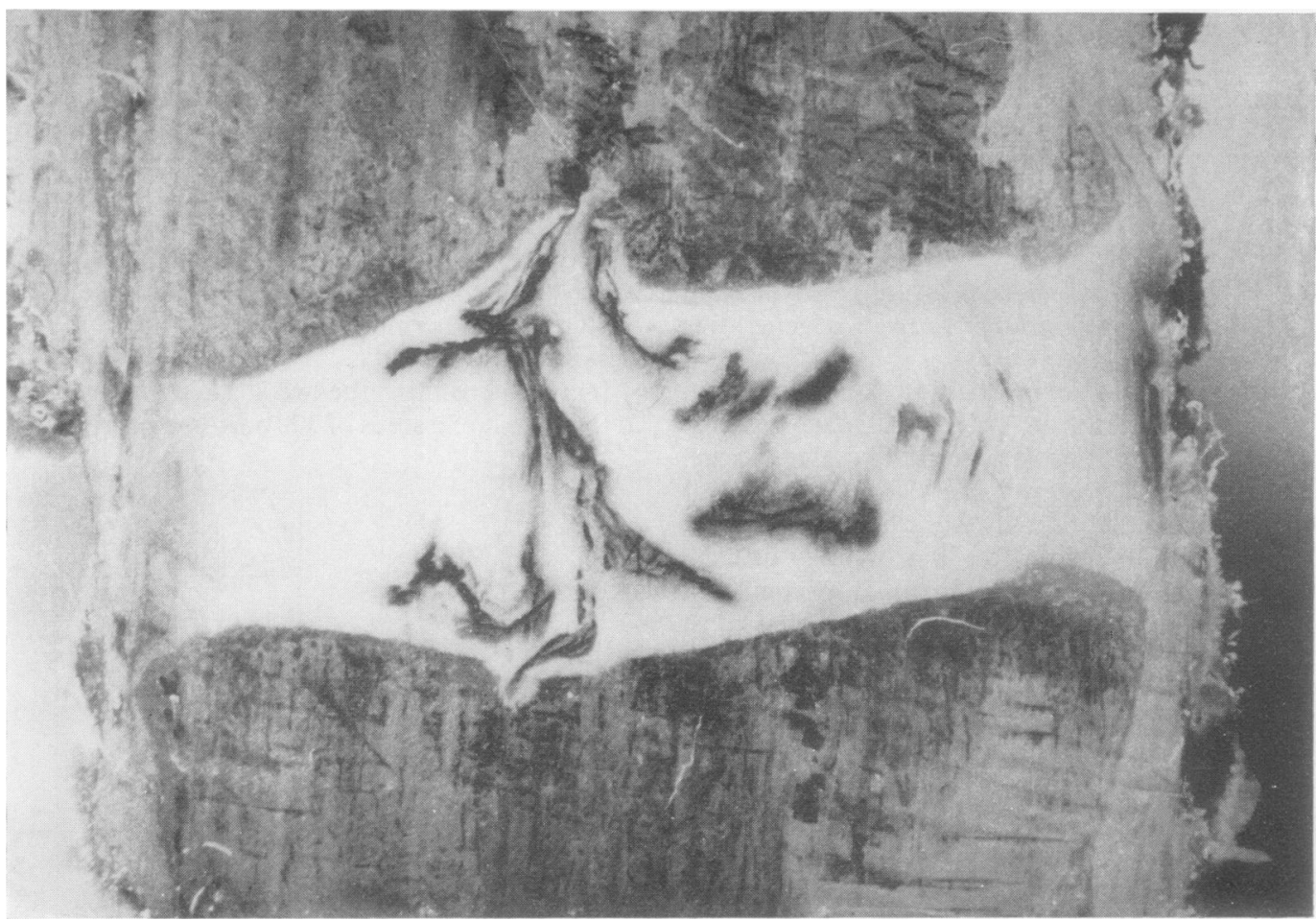

FIG. 9 Sagittal section of a disc showing bursts into the vertebral bodies above and below

tively were from a spine that, on $x$ ray, was very osteoporotic.

The sites of bursting and their relation to the nuclear morphology are shown in Table IV (above). Of the 78 discs, ten failed to burst at 1,000 p.s.i. and these all had either normal nuclei, posterolateral winging, or irregular nuclei. The most common site of bursting was directly into the vertebral body above or below the disc (Fig. 9). Posterolateral bursting was the next most common site and occurred in the direction of disc prolapse producing nerve root compression (Fig. 10). Central posterior bursting (Fig. 11) occurred only in discs showing posterior position of the nucleus, irregular nucleus, central posterior hernia, or degeneration. Generalized bursting around the whole disc circumference occurred in one disc with a degenerate nucleus.

Most globular discs burst directly into the vertebral body. Failure to burst occurred in a few and in only two was there a posterolateral burst. Similarly, despite well-marked posterolateral winging, eleven of this group of fifteen either burst into the vertebral body or failed to burst, whereas only four produced a posterolateral burst which occurred in the direction of the previous winging. On the other hand, when there was a posterolateral hernia of the nucleus, bursting always took place through this. An irregular nucleus did not appear to predispose towards easy bursting and six of these seven either failed to burst or burst into the vertebral bodies. Of the four discs 


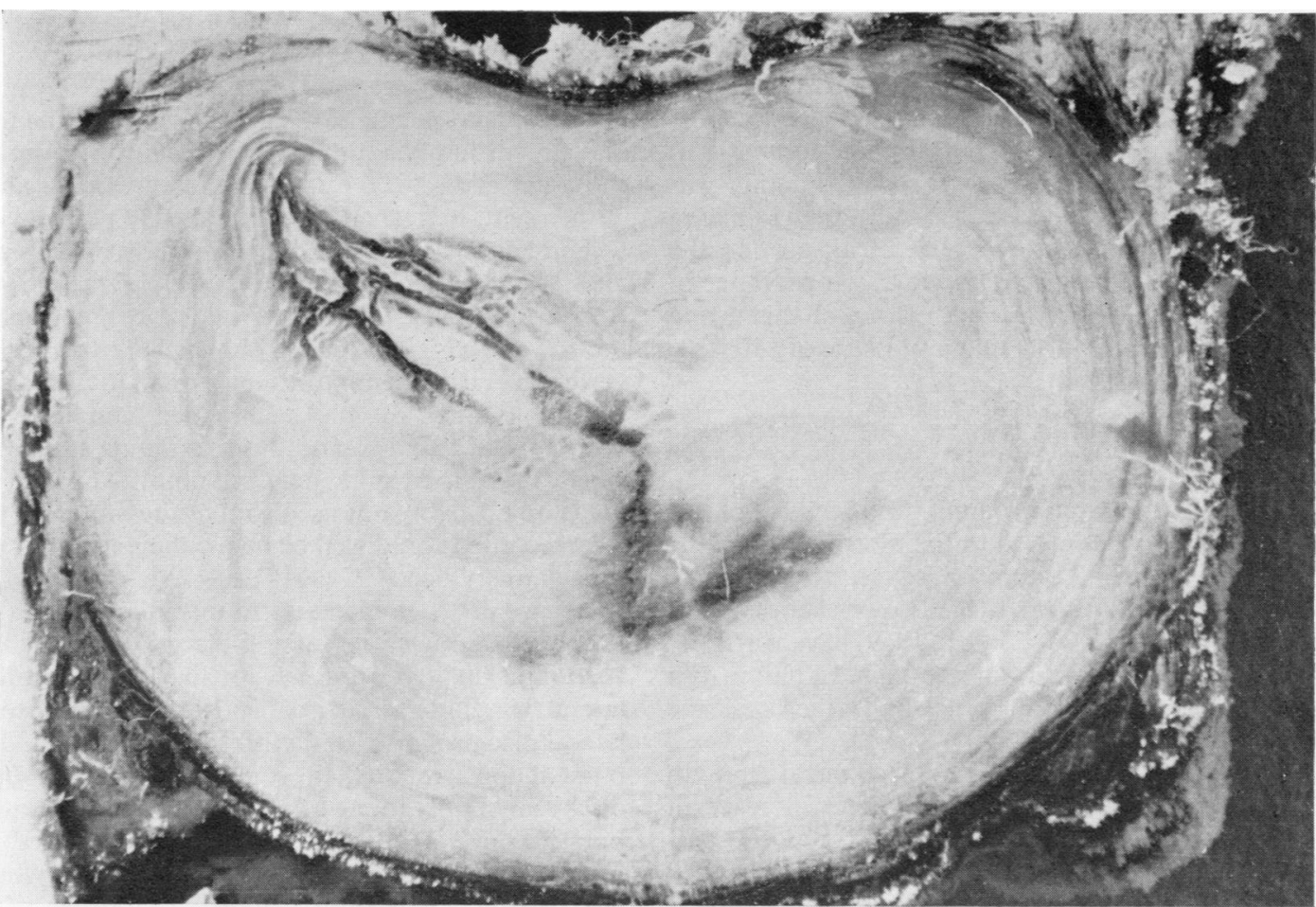

FIG. 10 Posterolateral bursting seen on horizontal section of the disc

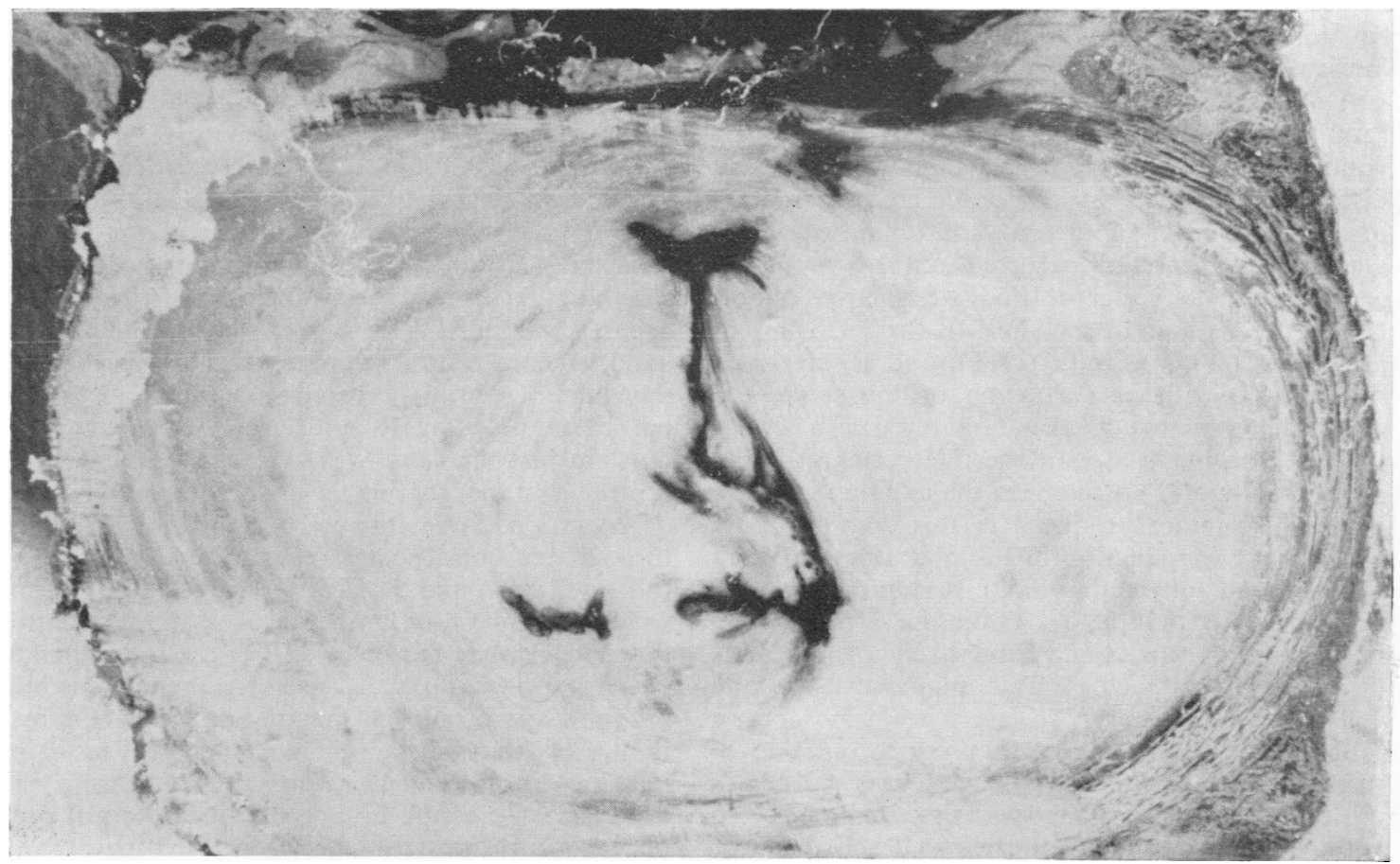

FIG. 11 Central-posterior bursting seen on horizontal section of the disc 
with posterior position of the nucleus, one burst directly backwards at the relatively low pressure of 200 p.s.i. On the other hand, another posterior burst in this group occurred at 1,000 p.s.i. Central posterior hernia resulted in a central posterior burst at relatively low pressures. This form of bursting was most common in degenerate discs, although in one of this group there was a generalized leak around the circumference of the disc. Despite the appearance of disc degeneration, the strength of one of this group appeared intact and it burst at a pressure of 880 p.s.i. into the vertebral body.

\section{Discussion}

In this study the strength and site of failure of the entire disc has been related to the morphology of the nucleus pulposus. A number of authors (Virgin, 1951 ; Evans and Lissner, 1954; Brown, Hansen, and Yorra, 1957; Roaf, 1960; Smith, 1969) have vertically loaded isolated segments of the spinal column but none made any study of the preceding structure of the intervertebral disc.

The present study relates the mechanical strength of the disc to stress induced by direct increase of intranuclear pressure. This method of creating pressure within the disc is artificial and may not accurately represent the mechanical changes occurring in life. Again, this model reproduces only one type of stress to which the human spine is submitted. It may be that flexion or torsion of the spine (Markolf, 1972) is of equal importance. These reservations must be borne in mind in interpreting these results.

A globular nucleus pulposus was the most common form found. This shape was uniformly present in the younger spines and is regarded as the normal. These discs showed a high resistance to increases in intranuclear pressure. In four disc failure did not occur, and in 22 the bursting occurred upwards or downwards into the vertebral body. Similarly, Virgin (1951), Evans and Lissner (1954), Brown, Hansen, and Yorra (1957), Smith (1969), and Roaf (1960) found that, with axial loading of the spine, the vertebral end-plate bulged and fractured with herniation of disc material into the intervertebral body. Axial loading did not damage the annulus fibrosus. End-plate rupture produced in this way is clearly analogous to production of the nodes described by Schmorl and Junghanns (1959). It is interesting and not unexpected that the discs from the spine showing marked osteoporosis burst at relatively low pressures into the vertebral bodies. This mimics osteoporotic collapse of vertebrae.

The pressures necessary to produce bursting of these globular discs into the vertebral end-plates must obviously be compared with those to be expected within the disc during life. Bartelink (1957) calculated that the total force acting on the L5/S1 disc could be as much as $2,000 \mathrm{lb}$. wt. With a disc area of about 4 sq. in., this would represent a mean pressure of up to 500 p.s.i. Nachemson and Morris (1964) made measurements in vivo of the pressures within the third and fourth lumbar discs. When sitting they were of the order of 100-200 p.s.i. The pressures were about 30 per cent. less when standing and 50 per cent less when reclining. Heavy lifting, especially when seated and bending forwards, could double these intranuclear pressures. These latter values are approaching the lower end of the range shown here to produce vertebral end-plate fractures in normal discs. Because of the nature of the techniques employed by Nachemson and Morris, the maximum stresses to which the human spine may be submitted in normal life were probably not used so that the pressures that they recorded could well be below the maximum that may actually occur. Clearly excessive stresses in the spine can produce increases in intranuclear pressure that damage the vertebral end-plates.

At first sight it would seem likely that posterolateral winging would predispose towards posterolateral disc prolapse. In fact this is not so. Such discs burst at approximately the same pressures as globular discs and in only four of the fifteen did posterolateral bursting develop. Similarly, the strength of discs with irregular nuclei appeared intact. By contrast, when a posterolateral extension reached the border of the vertebra (posterolateral hernia), it then burst easily in that direction.

These results imply that increases in intranuclear pressure alone do not normally produce posterolateral prolapse. It is only when a considerable weakness in the posterolateral direction is already present that posterolateral prolapse occurs.

Posterior position of the nucleus was described by Jayson and Barks (1973) and suggested as being a possible mechanism in the production of non-specific back pain. It did not appear to predispose towards easy bursting of the disc although, when bursting did occur, it was more likely to be posterior. On the other $\frac{\text { 의 }}{2}$ hand, when a central posterior hernia was present, $\rightarrow$ then bursting always occurred at low pressures in that particular direction. By and large, degenerate discs $N$ burst in just the same way. We can postulate that central posterior hernia is an early event in disc $\mathcal{N}$ degeneration. Later, there is loss of disc substance $\omega$ through this central posterior hernia and degeneration follows. Jayson and Barks (1973) described a spine ine which the upper four lumbar discs all showed central $\mathbb{\Phi}$ posterior herniae but the lowest disc was degenerate ${ }^{?}$ and it appeared on transverse section as if this had $\underset{T}{T}$ followed loss of nuclear material in the same direc- $\frac{\text { to }}{\vec{D}}$

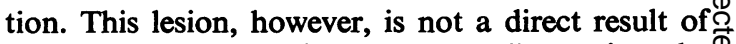
increases in intranuclear pressure. Increasing the $\stackrel{\mathbb{Q}}{\circ}$ intranuclear pressure in globular discs did not pro-duce a central posterior hernia or bursting on any occasion. 
This study emphasizes the wide variety of changes in morphology that may be found in the nucleus pulposus despite a normal $x$ ray of the spine. The different forms of disc failure under stress could not be predicted by simple radiological examination.

\section{Summary}

The morphology of the nucleus pulposus was determined by discography in 78 cadaveric discs and they were classified into the following groups: globular, posterolateral winging, posterolateral hernia, posterior position, irregular, central posterior hernia, and degenerate. Each nucleus was burst with a hydraulic pump and the pressure and site of bursting determined. Globular, posterolateral winging, and irregular nuclei required high pressures to produce failure and this usually occurred by fracture of the vertebral end plates. Posterolateral hernia, central posterior hernia, and degenerate nuclei burst at low pressures in the posterolateral and posterior directions.

Increase in intranuclear pressure will not usually produce the types of disc prolapse associated with nerve root damage unless there is a gross abnormality of disc structure.

We wish to thank Mr. D. Hayward and Dr. R. Sellin for their help and the Arthritis \& Rheumatism Council, the Medical Research Council, and the Association of Friends of the Royal National Hospital for Rheumatic Diseases for research grants that enabled this study to be performed.

\section{References}

BARTelink, D. L. (1957) J. Bone Jt Surg., 39B, 718 (The role of abdominal pressure in relieving the pressure on the lumbar intervertebral discs)

Brown, T., Hansen, R. J., AND Yorra, A. J. (1957) Ibid., 39A, 1135 (Some mechanical tests on the lumbosacral spine with particular reference to the intervertebral discs)

Evans, F. G., AND LISSNER, H. R. (1954) Ibid., 36A, 185 (Strength of intervertebral discs)

JAYSON, M. I. V., AND BARKS, J. S. (1973) Ann. rheum. Dis., 32, 10 (Structural changes in the intervertebral discs)

MARKOLF, K. L. (1972) J. Bone Jt Surg., 54A, 511 (Deformation of the thoracolumbar intervertebral joints in response to external loads)

NACHEMSON, A., AND MoRRIS, J. M. (1964) Ibid., 46A, 1077 (In vivo measurements of intradiscal pressure)

ROAF, R. (1960) Ibid., 42B, 810 (A study of the mechanics of spinal injuries)

SCHMORL, G., AND JunghanNs, H. (1959) 'The Human Spine in Health and Disease', trans. S. P. Wilk and L. S. Goin. Grune and Stratton, New York and London.

SMITH, F. P. (1969) J. Neurosurg., 30, 134 (Experimental biomechanics of intervertebral disc rupture through a vertebral body)

VIRGIN, W. J. (1951) J. Bone Jt Surg., 33B, 607 (Experimental investigations into the physical properties of the intervertebral disc) 